\title{
Detection of HPV in oral rinse samples from OPSCC and non-OPSCC patients
}

\author{
Juliet Dang ${ }^{1 *}$, Qinghua Feng ${ }^{5}$, Keith D. Eaton², Hona Jang ${ }^{5}$ and Nancy B. Kiviat ${ }^{3,4}$
}

\begin{abstract}
Background: Due to the increasing rates of oropharyngeal cancer, oral HPV infection is a significant concern. Methods for detecting oral HPVs is not standardized as there are different techniques available. We propose that use of oral rinse samples to detect for HPVs is a suitable technique within a clinic setting. Thus, our main objective is to study HPV detection in oral rinse samples.

Methods: In our study, we used oral rinse sample collection coupled with real-time PCR to detect for HPVs types 16 and 18, and preferentially amplified FAP PCR samples to detect for a broad range of HPVs, in oropharyngeal squamous cell carcinoma (OPSCC), non-OPSCC, and healthy patients.
\end{abstract}

Results: Thirty three percent of 100 cancer patients were positive for any type of HPV; of those 23 were positive for HPV16. Only 1 of 110 healthy controls was positive (this subject was positive for HPV18).

Conclusion: Our results indicate that HPV detection in oral rinse samples may be useful as a screening tool to detect HPV-associated oral cancers.

\section{Background}

Tissues infected by human papillomavirus (HPV) have the ability to evolve into an HPV-associated cancer. This is likely due to a field effect where HPV can modify regular cell functions resulting in malignancy. Though we know how to test for HPV-related cancers, there is currently no standard for detecting HPV infection [1], and screening for HPV could identify individuals at risk for head and neck squamous cell carcinoma (HNSCC). Speaking of which, HNSCC cases associated with HPV have been a challenge to screen for, especially oral cavity squamous cell carcinoma (OSCC) and oropharyngeal squamous cell carcinoma (OPSCC) cases, which are subsets of HNSCC. The oropharyngeal area includes the base of the tongue, soft palate, tonsils, and tonsillar region, with the oral cavity encompassing the rest of the interior tissues of the mouth. The most common methods for HPV detection within the mouth and oropharynx begin with collection of cells with a cotton swab, cytobrush, or a mouth rinse [2], followed by the use of PCR-based assays or DNA in situ hybridization

\footnotetext{
* Correspondence: jhtdang@gmail.com

'Oral Health Sciences, University of Washington, Box 3574751959 NE Pacific St., Seattle, WA 98195, USA

Full list of author information is available at the end of the article
}

[3]. However, there are challenges present for certain techniques. For example, the use of a swab/brush limits the amount of mucosa that is sampled, and obtaining a sample from a non-visible lesion within the tonsillar crypt may not be feasible [4]. The base of the tongue is not entirely accessible either as there is both flat mucosa and tonsillar tissue, thus increasing the risk for false negatives [5]. We chose to use a mouth rinse technique for sample collection as it is non-invasive, quick, and simple for the patient.

Analyzing p16 expression has been used as a biomarker for HPV-associated OSCC/OPSCC, but studies have reported that p16 overexpression is not always present in cases involving oncogenic HPVs [6-9]. A recent study concluded that p16 should not be used as a surrogate marker for HPV infection in oral cancers due to poor concordance between the two [10]. Previous to this, Pannone et al. also stated that p16 immunohistochemistry (IHC) alone does not prove to be a reliable method in HPV detection for OSCC/OPSCC cases [11]. Within our study, we obtained information for p16 testing to see whether or not our HPV data was in concordance.

OPSCC incidence in developed countries has increased significantly and HPV infection is proposed to be the main 
factor [12]. Risk factors for oral HPV infection include certain sexual practices [13-16]; number of lifetime partners and number of recent sex partners, older age, being male, and current cigarette smoking $[17,18]$. The most prevalent type of HPV associated with oral infection is type $16[17,19]$, which has been demonstrated to be oncogenic in HNSCCs [20]. A worldwide systematic review of HNSCC biopsies demonstrated HPV16 in $31 \%$ of OPSCC cases; $16 \%$ of OSCC cases; and $17 \%$ of laryngeal SCC cases [21]. HPV type 18 also appears to play a significant role in carcinogenesis, especially in the oropharynx $[22,23]$.

With the rise of OPSCCs it is imperative to have a gold-standard technique in place for oral HPV detection. Collecting samples from the oral cavity and oropharynx for the detection of oral HPVs should be quick, noninvasive, inexpensive, and sufficient in HPV DNA collection. In our study, we investigated oral rinse samples coupled with real-time PCR Taqman assays to detect for HPV types 16 and 18, which is sensitive and specific. To detect for a broad range of HPVs, we preferentially amplified the oral rinse samples from cancer cases, and used fluorescent arbitrarily primed (FAP) PCR, a general PCR method using degenerate HPV primers.

\section{Study population}

Between 2011 and 2013, we recruited 76 OPSCC and 24 non-OPSCC patients from the Seattle Cancer Care Alliance (Seattle, WA), and 110 healthy subjects from University of Washington Dental Clinic (Seattle, WA). Non-OPSCC cases included patients with OSCC, laryngeal, sinus, and supraglottis cancers. We screened the schedules of five oncologists in order to identify eligible cancer patients, and discussed our study at their appointment. One patient declined due to mouth sores and sensitivity. 21/100 cancer patients had already begun treatment and of these 21 patients: 18 patients had treatment less than 21 days before sampling, two had over 30 days of treatment, and one patient had treatment for 7 months. Healthy subjects were randomly selected within the student dental clinic, one patient declined to take part in the study. Inclusion requirements for the healthy population included being: cancer-free, not pregnant, HIV-free, and over the age of 16. Each patient signed written consent forms to participate in the study (IRB \#7490 approved April 9, 2014), and answered a simple health questionnaire. Gender, age, race, smoking, alcohol, and marijuana history were recorded for all subjects. Charts for a subset of our patients were reviewed for p16 immunohistochemistry (IHC) and HPV testing.

\section{Methods}

\section{Collection \& DNA purification methods}

For sample collection, all patients rinsed and gargled for $30 \mathrm{~s}$ with Original Mint Scope ${ }^{\bullet}$ mouthwash (Procter \& Gamble). Four normal healthy individuals requested to use Crest $^{\oplus}$ Alcohol-free mouthwash due to a history of alcoholism. Oral rinse samples were centrifuged for $15 \mathrm{~min}$. at $4{ }^{\circ} \mathrm{C}$ to form a pellet, the supernatant was discarded, and the pellet was placed in $-80{ }^{\circ} \mathrm{C}$ until further processing. The Puregene ${ }^{\circ}$ DNA Purification Kit was used to isolate genomic DNA from the buccal cell pellet within the mouthwash samples (Qiagen item \#158467, manufacturer's protocol was followed).

All human subjects IRB protocols and regulations were followed under the Fred Hutchinson Cancer Research Center guidelines (IRB \#7490 approved April 9, 2014).

\section{HPV \& analytic methods}

Taqman real-time PCR assays were used for detection on the ABI Prism 7900 Sequence Detection System with 40 cycles in a reaction (denaturation at $95^{\circ} \mathrm{C}$, annealing and extension at $60{ }^{\circ} \mathrm{C}$ ). Absolute quantification was used to determine HPV16 and 18 viral load, and total human genomic DNA in the sample was determined on Alu sequences. Serial dilutions of human genomic DNA and full length HPV16 and 18 plasmids, of known concentrations, were used as standard curves.

\section{HPV16 E7 Primers \\ Forward: CGGACAGAGCCCATTACAATATT \\ Reverse: CGCACAACCGAAGCGTAGA \\ HPV16 E7 Probe: TAACCTT(T/C)TGTTGCAAGTGT HPV18 E7 Primers: \\ Forward: CCGACGAGCCGAACCA \\ Reverse: TGGCTTCACACTTACAACACATACA \\ HPV18 E7 Probe: AACGTCACACAATGTT}

In order to increase the efficiency of HPV detection, we used the multiply-primed rolling-circular amplification technique (MP-RCA) to preferentially amplify unknown, circular HPV DNA. MP-RCA has been demonstrated to amplify circular DNA templates up to 107-fold [24]. The TempliPhi 100 Amplification Kit (Amersham Biosciences) protocol was followed.

The FAP PCR published protocol was followed to detect for a broad range of HPV types where primers were developed from conserved L1 regions [25]. We only performed this technique on the cancer case samples (Fig. 1).

We categorized smoking history as follows: nonsmoker (0 packs); light smoker (<1pack/week); moderate smoker ( $\geq 1$ pack/week $\leq 1$ pack/day); heavy smoker ( $\geq 1$ pack/day). For those who smoked cigars or chewed tobacco we calculated to the equivalent of packages of cigarettes smoked. Alcohol history was categorized as 




Fig. 1 FAP PCR results on an electrophoresis gel. An expected band of $\sim 480$ bp indicates an HPV positive sample

follows: none (never drinks); rarely/occasionally (1 drink every 1-2 months); light (1-6 drinks/week for females, 1-13 drinks/week for males); moderate (7 drinks/week for females, 14 drinks/week for males); heavy ( $>7$ drinks/ week for females, $>14$ drinks/week for males).

All data analysis was done using Stata MP 13.1 (StataCorp LP, Texas, USA).

\section{Results}

Oral cancer subjects with OPSCC and non-OPSCC were more likely to be male than control subjects without cancer, as at least $83 \%$ of subjects in each cancer type were male, compared to only $46 \%$ of controls (Table $1 ; p<0.001$ ). Cancer cases were also older than controls, as $>80 \%$ of cases, regardless of cancer type, were 50 years of age or older compared to only $63 \%$ of controls $(p<0.001)$. Subjects with OPSCC and non-OPSCC were similar to subjects without cancer with respect to race $(p=0.30)$ and ethnicity $(p=0.62)$ and were predominately non-Hispanic Caucasians. Those who had cancer (39\% OPSCC, $54 \%$ nonOPSCC; $p<0.001)$ were more likely to be heavy smokers compared to those with no cancer (32\%). Heavy alcohol history was prevalent in $33 \%$ of OPSCC and in $33 \%$ of OSCC patients $(p=0.015)$ compared to only $12 \%$ of non-cancer subjects. Marijuana use was mainly observed in cancer cases (11\% OPSCC, $4 \%$ OSCC; $p=0.010)$ and rarely in controls $(0.91 \%)$. Cases of both cancer types (33\% OPSCC, 33 \% non-OPSCC; $p<0.001)$ were more likely to have detectable HPV than healthy controls (0.9\%), and specifically type 16 (25\% OPSCC, $17 \%$ non-OPSCC; $p<0.001$ ) detected in their oral rinse samples compared to controls. HPV18 detection did not vary by study group and was detected in a single sample from a control subject ( $p$ $=0.63$ ), and none in the cancer cases. Our method for HPV detection had a sensitivity of $33 \%$ and specificity of $99 \%(p<0.001)$.

Twenty-two HPV positive samples were tested for p16 prior to sampling, and only one tested negative for p16. However, 26 samples that were negative for HPV were positive for p16 (Table 2). It should be noted that three of the 26 patients $(p=0.085)$ underwent treatment (ie. chemotherapy, radiation therapy, excision) prior to sampling, which could affect the presence of prior HPV infection. HPV was marginally associated with p16 detection $(p=0.076)$; of patients who were HPV positive, $96 \%$ had a positive p16 test; only one sample that was positive for HPV tested negative for p16. Amongst HPV negative patients, $79 \%$ were p16 positive. Only two case patients had HPV screening completed before sampling and both were negative for HPV in our tests and the screening.

\section{Discussion}

Patient sample collection can be a difficult and time consuming task especially when the researcher is interrupting an appointment. Also, many individuals have sensitive gag reflexes, thus if a brush or swab technique is used to scrape the back of the throat, obtaining a sample may be quite difficult without the aid of a topical anesthetic. This is why it is imperative to have a sampling technique in place that is non-invasive and quick, yet sufficient for detection of HPV. Our study has demonstrated that oral rinse sample collection is an unobtrusive method to use for detection of oral HPVs. This is in concordance with a study comparing oral rinse and cytology brush sampling, which concluded that oral rinses were the best choice for sampling from the oral cavity in order to detect for HPV [26].

We used Scope ${ }^{\circ}$ because it was observed to have excellent preservation of high-molecular-weight DNA quality, and it is more palatable than most other rinse media [27]. Four control patients requested to rinse with Crest Pro-Health ${ }^{\circ}$ non-alcoholic mouthwash. We did not see differences in DNA quantity (data not shown), however more research is required to see if there is a difference with quantity as well as quality.

Quantifying viral load may be crucial in determining whether HPV-positive OPSCC/OSCCs are unquestionably the result of HPV infection [28]. The gold-standard for HPV viral load assessment is real-time PCR $[29,30]$. One study demonstrated OPSCC to have a viral load of $\sim 80,000$ times higher than OSCC and other HNSCCs 
able 1 Demographics amongst all subjects in non-cancer and cancer cases

\begin{tabular}{|c|c|c|c|c|}
\hline & No cancer & OPSCC & Non-OPSCC & $p$-value \\
\hline & $n=110$ & $n=76$ & $n=24$ & \\
\hline \multicolumn{5}{|l|}{ Gender } \\
\hline Male & $51(46.36 \%)$ & $63(82.89 \%)$ & 20 (83.33 \%) & \multirow[t]{2}{*}{$<0.001$} \\
\hline Female & $59(53.64 \%)$ & $13(17.11 \%)$ & $4(16.67 \%)$ & \\
\hline \multicolumn{5}{|l|}{ Grouped age } \\
\hline $20-39$ & 27 (24.55 \%) & $1(1.32 \%)$ & 1 (4.17\%) & \\
\hline $40-49$ & $13(11.82 \%)$ & $10(13.16 \%)$ & $2(8.33 \%)$ & \\
\hline $50-59$ & $21(19.09 \%)$ & $29(38.16 \%)$ & 11 (45.83 \%) & \multirow[t]{3}{*}{$<0.001$} \\
\hline $60-69$ & $29(26.36 \%)$ & $30(39.47 \%)$ & 8 (33.33 \%) & \\
\hline $70+$ & $20(18.18 \%)$ & $6(7.89 \%)$ & 2 (8.3\%) & \\
\hline \multicolumn{5}{|l|}{ Race } \\
\hline Asian & $5(5.55 \%)$ & $2(2.63 \%)$ & $1(4.17)$ & \\
\hline Black & $6(5.45 \%)$ & $1(1.32 \%)$ & 0 & \\
\hline White & $92(83.64 \%)$ & $65(85.53 \%)$ & $21(87.50 \%)$ & \multirow[t]{3}{*}{0.30} \\
\hline Other & 7 (6.36 \%) & $4(5.26 \%)$ & 1 (4.17\%) & \\
\hline Unknown & 0 & $4(5.26 \%)$ & $1(4.17 \%)$ & \\
\hline \multicolumn{5}{|c|}{ Ethnicity (Hispanic/Latino) } \\
\hline Yes & $4(3.64 \%)$ & $2(2.63 \%)$ & 0 & \multirow[t]{2}{*}{0.62} \\
\hline No & 106 (96.36 \%) & $74(97.37 \%)$ & $24(100 \%)$ & \\
\hline \multicolumn{5}{|l|}{ Smoking history } \\
\hline Non-smoker & $51(46.36 \%)$ & $21(27.63 \%)$ & 5 (20.83\%) & \\
\hline Light smoker & $1(0.91 \%)$ & $14(18.42 \%)$ & $2(8.33 \%)$ & \multirow[t]{3}{*}{$<0.001$} \\
\hline Moderate smoker & 23 (20.91 \%) & $11(14.47 \%)$ & $4(16.67 \%)$ & \\
\hline Heavy smoker & 35 (31.82 \%) & $30(39.47 \%)$ & 13 (54.17 \%) & \\
\hline \multicolumn{5}{|l|}{ Alcohol history } \\
\hline None & $24(21.82 \%)$ & $7(9.21 \%)$ & $3(12.50 \%)$ & \multirow{5}{*}{0.015} \\
\hline Rarely/occasionally & $16(14.55 \%)$ & $14(18.42 \%)$ & $4(16.67 \%)$ & \\
\hline Light & 54 (49.09\%) & $27(35.53 \%)$ & 9 (37.50 \%) & \\
\hline Moderate & $3(2.73 \%)$ & $3(3.95 \%)$ & 0 & \\
\hline Heavy & $13(11.82 \%)$ & $25(32.89 \%)$ & 8 (33.33 \%) & \\
\hline \multicolumn{5}{|l|}{ Any Marijuana use } \\
\hline Yes & $1(0.91 \%)$ & $8(10.53 \%)$ & 1 (4.17\%) & \multirow[t]{2}{*}{0.010} \\
\hline No & 109 (99.09 \%) & $68(89.47 \%)$ & 23 (95.83 \%) & \\
\hline Any HPV & $1(0.91 \%)$ & $25(32.89 \%)$ & 8 (33.33 \%) & $<0.001$ \\
\hline HPV 16 positive & 0 & $19(25.00 \%)$ & 4 (16.67 \%) & $<0.001$ \\
\hline HPV 18 positive & 1 (0.91 \%) & 0 & 0 & 0.63 \\
\hline
\end{tabular}

a Data for "No Cancer" is associated with published data from Prevalence of HPV types 16 and 18 within a dental student clinic setting (J Dang et al.)

Table 2 p16 and any HPV

\begin{tabular}{llll}
\hline Any HPV & p16 test & & $p$-value \\
\hline & Positive & Negative & 0.076 \\
& $n=48$ & $n=8$ & \\
Yes & $22(95.65 \%)$ & $1(4.35 \%)$ & \\
No & $26(78.79 \%)$ & $7(21.21 \%)$ & \\
\hline
\end{tabular}

[29]. Our results showed no significant differences between the two cancer groups (Fig. 2). As well, differences in results could be due to the authors using freshfrozen biopsies where only a small portion of the oral cavity or oropharynx is sampled. Oral rinse samples may allow for a more effective collection of oral cells for HPV detection. Variation in findings warrants further 


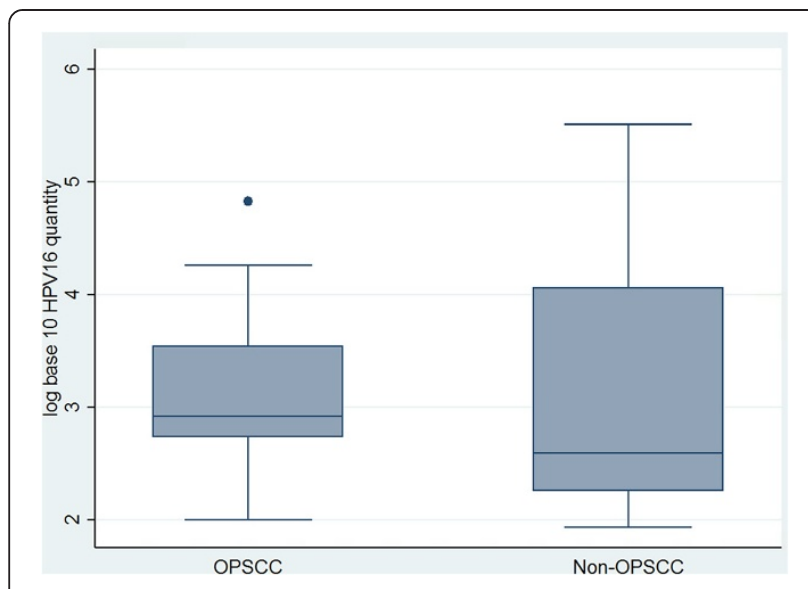

Fig. 2 Comparison of HPV16 viral load (copies/ng DNA) between the two cancer groups. No statistically significant difference was seen $(p=0.40)$. The gray boxes demonstrate range from lower to upper quartiles. The median is represented by a horizontal line. Maximum and minimum values are indicated by the vertical lines. Viral load variation between each group was demonstrated. The median viral load in OPSCC was slightly higher than non-OPSCC cases

investigation of viral load in association with subsets of HNSCC.

The one patient with OPSCC, who had undergone treatment for 7 months prior to sampling, was positive for HPV, specifically type 16 . This case is unique as undergoing several months of treatment should eradicate the virus unless if the infection was recent. It should be noted that the patient had a heavy smoking and drinking history. More research on prevalence of HPV infection after radiation/chemotherapy is warranted.

One major limitation was not having DNA from tumor tissue to compare HPV detection. The tissue samples were not available to us, but would have acted as a gold standard within our study. Other limitations to our study include: our results demonstrating a low sensitivity for HPV detection in cancer patients, but with a very high specificity; we could not control how well a patient would gargle and swish the mouthwash, which will have an effect on the quantity and quality of DNA collected; Scope ${ }^{\circ}$ has a strong mint taste, which may not be suitable for those with sensitive mouths; small sample size; not detecting for HPV RNA to show active infection; and FAP PCR is sensitive enough to detect for a broad range of HPVs, but some HPVs may not be detected due to the generality of the designed primers [25].

p16 testing is usually only performed in cases where they do not fit the traditional risk factors (ie. significant tobacco and alcohol use history), and HPV testing is rarely done. This is something that needs to be changed during diagnosis due to the increase in HPV-associated OPSCCs.

\section{Conclusions}

From our results we demonstrated that preferentially amplified oral rinse samples with HPV detection from real-time PCR Taqman assays and FAP PCR, is a usable method overall, which could be used within a clinic setting. More specific studies will need to be done to determine whether mouth rinses do actually reflect, in cases, the type of HPV associated with the cancerous lesion.

\section{Abbreviations}

OSCC: Oral squamous cell carcinoma; OPSCC: Oropharyngeal squamous cell carcinoma; HNSCC: Head and neck squamous cell carcinoma; RT-PCR: Realtime polymerase chain reaction; FAP PCR: Fluorescent arbitrarily primed polymerase chain reaction; MP-RCA: Multiply-primed rolling-circular amplification.

\section{Competing interests}

The authors declare they have no competing interests.

\section{Authors' contributions}

JD completed all experiments, analyzed all data, and wrote the manuscript. NBK and QF conceived/designed the study, and reviewed/edited the manuscript. KDE was the collaborative oncologist for the study who helped with sample collection, and with review/editing of the paper. HJ assisted in sample collection. All authors read and approved the final manuscript.

\section{Acknowledgements}

Source of funding from University of Washington's Royalty Research Fund.

\section{Author details}

${ }^{1}$ Oral Health Sciences, University of Washington, Box 3574751959 NE Pacific St., Seattle, WA 98195, USA. ${ }^{2}$ Seattle Cancer Care Alliance, 825 Eastlake Ave E, Seattle, WA 98109, USA. ${ }^{3}$ Pathology, University of Washington, Seattle, WA, USA. ${ }^{4}$ Harborview Medical Center, 908 Jefferson, Seattle, WA 98104, USA.

${ }^{5}$ University of Washington, 1959 NE Pacific St., Seattle, WA 98195, USA.

Received: 23 April 2015 Accepted: 8 October 2015

Published online: 15 October 2015

\section{References}

1. Westra WH. Detection of human papillomavirus (HPV) in clinical samples: evolving methods and strategies for the accurate determination of HPV status of head and neck carcinomas. Oral Oncol. 2014:50(9):771-9.

2. Garcia-Closas M, Egan KM, Abruzzo J, Newcomb PA, Titus-Ernstoff L, Franklin T, et al. Collection of genomic DNA from adults in epidemiological studies by buccal cytobrush and mouthwash. Cancer Epidemiol Biomark Prev. 2001;10(6):687-96.

3. Holmes BJ, Westra WH. The expanding role of cytopathology in the diagnosis of HPV-related squamous cell carcinoma of the head and neck. Diagn Cytopathol. 2014;42(1):85-93.

4. Fakhry C, Rosenthal BT, Clark DP, Gillison ML. Associations between oral HPV16 infection and cytopathology: evaluation of an oropharyngeal "paptest equivalent" in high-risk populations. Cancer Prev Res. 2011;4(9):1378-84.

5. Lingen MW. Brush-based cytology screening in the tonsils and cervix: there is a difference! Cancer Prev Res. 2011;4(9):1350-2.

6. Smeets SJ, Hesselink AT, Speel EJ, Haesevoets A, Snijders PJ, Pawlita M, et al. A novel algorithm for reliable detection of human papillomavirus in paraffin embedded head and neck cancer specimen. Int J Cancer. 2007;121(11):2465-72.

7. Fakhry C, Westra WH, Li S, Cmelak A, Ridge JA, Pinto H, et al. Improved survival of patients with human papillomavirus-positive head and neck squamous cell carcinoma in a prospective clinical trial. J Natl Cancer Inst. 2008:100(4):261-9.

8. Stephen JK, Divine G, Chen KM, Chitale D, Havard S, Worsham MJ. Significance of p16 in site-specific HPV positive and HPV negative head and neck squamous cell carcinoma. Cancer Clin Oncol. 2013;2(1):51-61. 
9. Salazar CR, Anayannis N, Smith RV, Wang Y, Haigentz Jr M, Garg M, et al. Combined P16 and human papillomavirus testing predicts head and neck cancer survival. Int J Cancer. 2014;135(10):2404-12.

10. Ramshankar V, Soundara VT, Shyamsundar V, Ramani P, Krishnamurthy A. Risk stratification of early stage oral tongue cancers based on HPV status and p16 immunoexpression. Asian Pac J Cancer Prev. 2014;15(19):8351-9.

11. Pannone G, Rodolico V, Santoro A, Lo Muzio L, Franco R, Botti G, et al. Evaluation of a combined triple method to detect causative HPV in oral and oropharyngeal squamous cell carcinomas: p16 Immunohistochemistry, Consensus PCR HPV-DNA, and In Situ Hybridization. Infect Agents Cancer. 2012;7:4.

12. Chaturvedi AK, Anderson WF, Lortet-Tieulent J, Curado MP, Ferlay J, Franceschi $\mathrm{S}$, et al. Worldwide trends in incidence rates for oral cavity and oropharyngeal cancers. J Clin Oncol. 2013;31(36):4550-9.

13. Chaturvedi AK, Engels EA, Pfeiffer RM, Hernandez BY, Xiao W, Kim E, et al Human papillomavirus and rising oropharyngeal cancer incidence in the United States. J Clin Oncol. 2011;29(32):4294-301.

14. D'Souza G, Cullen K, Bowie J, Thorpe R, Fakhry C. Differences in oral sexual behaviors by gender, age, and race explain observed differences in prevalence of oral human papillomavirus infection. PLoS One. 2014;9(1):e86023.

15. Cook RL, Thompson EL, Kelso NE, Friary J, Hosford J, Barkley P, et al. Sexual behaviors and other risk factors for oral human papillomavirus infections in young women. Sex Transm Dis. 2014;41(8):486-92.

16. Gillison ML, Castellsague X, Chaturvedi A, Goodman MT, Snijders P, Tommasino M, et al. Comparative epidemiology of HPV infection and associated cancers of the head and neck and cervix. Int J Cancer. 2013.

17. Gillison ML, Broutian T, Pickard RK, Tong ZY, Xiao W, Kahle L, et al. Prevalence of oral HPV infection in the United States, 2009-2010. JAMA. 2012;307(7):693-703.

18. Fakhry C, Gillison ML, D'Souza G. Tobacco use and oral HPV-16 infection. JAMA. 2014;312(14):1465-7.

19. Hariri S, Unger ER, Sternberg M, Dunne EF, Swan D, Patel S, et al. Prevalence of genital human papillomavirus among females in the United States, the National Health and Nutrition Examination Survey, 2003-2006. J Infect Dis. 2011;204(4):566-73.

20. Gillison ML, Koch WM, Capone RB, Spafford M, Westra WH, Wu L, et al. Evidence for a causal association between human papillomavirus and a subset of head and neck cancers. J Natl Cancer Inst. 2000;92(9):709-20.

21. Kreimer AR, Clifford GM, Boyle P, Franceschi S. Human papillomavirus types in head and neck squamous cell carcinomas worldwide: a systematic review. Cancer Epidemiol Biomark Prev. 2005;14(2):467-75.

22. Mineta H, Ogino T, Amano HM, Ohkawa Y, Araki K, Takebayashi S, et al. Human papilloma virus (HPV) type 16 and 18 detected in head and neck squamous cell carcinoma. Anticancer Res. 1998;18(6B):4765-8.

23. Michaud DS, Langevin SM, Eliot M, Nelson HH, Pawlita M, McClean MD, et al. High-risk HPV types and head and neck cancer. Int J Cancer. 2014;135(7):1653-61.

24. Nelson JR, Cai YC, Giesler TL, Farchaus JW, Sundaram ST, Ortiz-Rivera M, et al. TempliPhi, phi29 DNA polymerase based rolling circle amplification of templates for DNA sequencing. BioTechniques. 2002;Suppl:44-7.

25. Forslund $\mathrm{O}$, Antonsson A, Nordin P, Stenquist B, Hansson BG. A broad range of human papillomavirus types detected with a general PCR method suitable for analysis of cutaneous tumours and normal skin. J Gen Virol. 1999;80(Pt 9):2437-43.

26. Steinau M, Reddy D, Sumbry A, Reznik D, Gunthel CJ, Del Rio C, et al. Oral sampling and human papillomavirus genotyping in HIV-infected patients. J Oral Pathol Med. 2012;41(4):288-91.

27. Heath EM, Morken NW, Campbell KA, Tkach D, Boyd EA, Strom DA. Use of buccal cells collected in mouthwash as a source of DNA for clinical testing Arch Pathol Lab Med. 2001;125(1):127-33.

28. Kreimer AR, Clifford GM, Snijders PJ, Castellsague X, Meijer CJ, Pawlita M, et al. HPV16 semiquantitative viral load and serologic biomarkers in oral and oropharyngeal squamous cell carcinomas. Int J Cancer. 2005;115(2):329-32.

29. Koskinen WJ, Chen RW, Leivo I, Makitie A, Back L, Kontio R, et al. Prevalence and physical status of human papillomavirus in squamous cell carcinomas of the head and neck. Int J Cancer. 2003;107(3):401-6.

30. Mellin H, Dahlgren L, Munck-Wikland E, Lindholm J, Rabbani H, Kalantari M, et al. Human papillomavirus type 16 is episomal and a high viral load may be correlated to better prognosis in tonsillar cancer. Int J Cancer. 2002;102(2):152-8.

\section{Submit your next manuscript to BioMed Central and take full advantage of:}

- Convenient online submission

- Thorough peer review

- No space constraints or color figure charges

- Immediate publication on acceptance

- Inclusion in PubMed, CAS, Scopus and Google Scholar

- Research which is freely available for redistribution 